\title{
Vapochromic Emission Observed for Amorphous Molecular Materials: Emitting Properties of $N, N$-Bis(9,9-dimethylfluoren-2-yl)-4-nitroaniline
}

\author{
Yuya Kitamura, Ayaka Sato, and Hideyuki Nakano* \\ Department of Applied Chemistry, Muroran Institute of Technology, \\ 27-1 Mizumoto-cho, Muroran, Hokkaido 050-8585, Japan \\ *nakano@mmm.muroran-it.ac.jp
}

\begin{abstract}
The title compound, $\mathrm{NO}_{2}$-F2PA, exhibited solvatochromic emission, that is, the emission spectra of hexane and toluene were different from each other and the emission was quenched in THF, acetone, ethanol, and acetonitrile. In addition, the amorphous film of $\mathrm{NO}_{2}$-F2PA exhibited vapochromic emission. Reddish orange emission of the film at ambient atmosphere changed to yellowish green one upon exposure to hexane vapor and recovered to the original after drying. On the other hand, the emission of the film was quenched upon exposure to THF and ethanol vapors.
\end{abstract}

Keywords: Emitting amorphous molecular material, Solvatochromic emission, Vapochromic emission

\section{Introduction}

Organic emitting materials that exhibit emission color changes in response to their surrounding environment or external stimuli are of interest from both viewpoints of fundamental sciences and practical applications. Solvatochromic emission and vapochromic emission are the phenomena of reversible emission color changes in response to the kind of solvent and/or vapor [1]. The emission color changes were suggested to be due to change in electronic states by interaction of the emitting molecule with surrounding molecules. Polymers possessing riboflavin moieties [2] and coordination polymers with multinuclear copper cluster [3] are examples that exhibit vapochromic luminescence. Recently, methylene blue film prepared onto titanium oxide was reported to exhibit rapid color change in response to moisture [4].

We have been made a part of studies of the creation of organic low molecular-mass materials that readily form amorphous glasses, namely amorphous molecular materials [5-9], and in due course we have found that 4-[bis(4-methylphenyl)amino]benzaldehyde and 4-[bis(4-methylphenyl)amino]acetophenone exhibited solvatochromic and vapochromic emissions [10-12]. These materials were also found to exhibit aggregation induced emission enhancement $[13,14]$. In addition, mixed amorphous films of these materials with p-toluene sulfonic acid exhibited emission modulations in response to exhaled breath, i.e., moisture around their films [15].

It is expected that emitting amorphous molecular materials with D-A structures exhibit emission color changes of their films in response to surrounding environment. $\mathrm{N}, \mathrm{N}$-Bis(9,9-dimethylfluoren-2-yl)-4-nitroaniline $\left(\mathrm{NO}_{2}-\mathrm{F} 2 \mathrm{PA}\right)$, which is an important precursor molecule for preparation of a variety of functional amorphous molecular

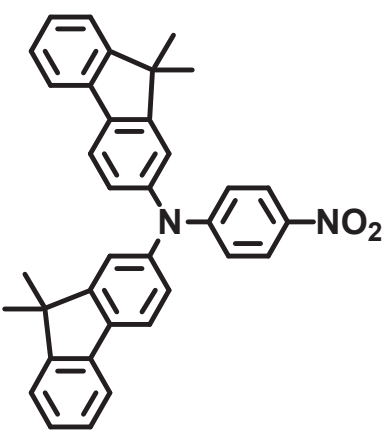

$\mathrm{NO}_{2}-\mathrm{F} 2 \mathrm{PA}$ 
materials $[16,17]$, is one of the promising candidates for such environmentally responsive emitting amorphous molecular materials. In the present study, we have newly investigated the emitting properties of $\mathrm{NO}_{2}-\mathrm{F} 2 \mathrm{PA}$ and found that the amorphous film exhibited vapochromic emission.

\section{Experimental}

$\mathrm{NO}_{2}$-F2PA could be prepared by the method described in our previous papers $[16,17]$. Crystalline sample of $\mathrm{NO}_{2}$-F2PA was purified by recrystallization from hexane and ethanol successively before use. Amorphous film of $\mathrm{NO}_{2}-$ F2PA was prepared onto a transparent glass substrate by spin-coating from THF solution. Differential scanning calorimetry (DSC) was carried out by means of a Seiko DSC6220 calorimeter. Emission spectra for solutions were measured by means of a FP-8300 spectrofluorometer (JASCO Co). With regard to the amorphous film, emission spectra were measured in the sealed quartz cell by means of Blue-Wave fiber multi-channel spectroscope (Stellarnet Inc.). The spectra upon exposure of the films to solvent vapors were measured in the cell in the presence of a small piece of cotton immersed in the solvent.

\section{Results and discussion}

Before investigation of emitting properties, DSC was performed. Figure 1 shows DSC curves of $\mathrm{NO}_{2}$-F2PA. When the crystalline sample was heated, a large endothermic peak due to melting was observed at $214{ }^{\circ} \mathrm{C}$. When the melt sample was cooled, an amorphous glassy state was obtained. When the glassy sample was again heated, glass transition phenomenon was observed at $103{ }^{\circ} \mathrm{C}$. On further heating, no phase transition was observed, suggesting that the glassy state was relatively stable. The amorphous film could easily be obtained by spin-coating method as well as other amorphous molecular materials.

$\mathrm{NO}_{2}$-F2PA was found to exhibit solvatochromic emission. That is, greenish yellow emission was observed for the hexane solution while the emission color turned to reddish yellow in toluene solution. As Fig. 2 shows, emission spectrum of $\mathrm{NO}_{2}-\mathrm{F} 2 \mathrm{PA}$ in toluene was considerably red-shifted relative to that in hexane. In contrast to these solutions, the emission of $\mathrm{NO}_{2}-\mathrm{F} 2 \mathrm{PA}$ was quenched in THF, acetone, ethanol, and acetonitrile. These results were suggested to be due to intramolecular charge transfer in the excited state

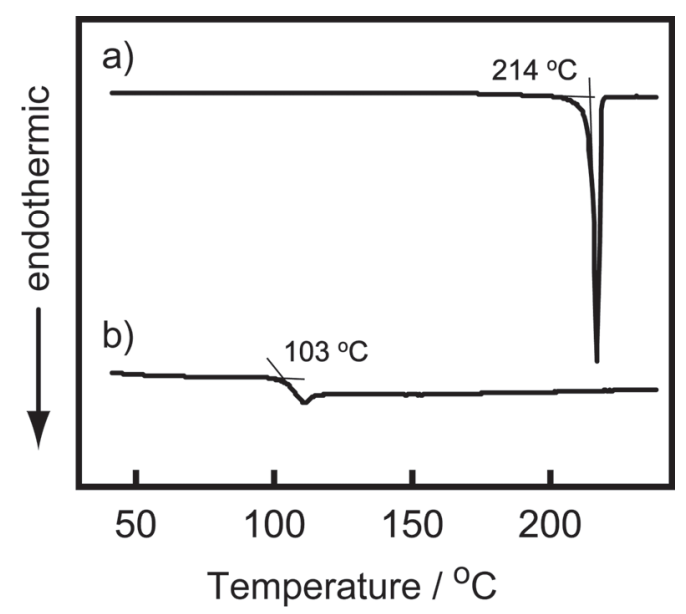

Fig. 1. DSC curves of $\mathrm{NO}_{2}-\mathrm{F} 2 \mathrm{PA}$. a) Crystalline sample. b) Glassy sample obtained by cooling the melt. Heating rate: $5^{\circ} \mathrm{C} \min ^{-1}$.

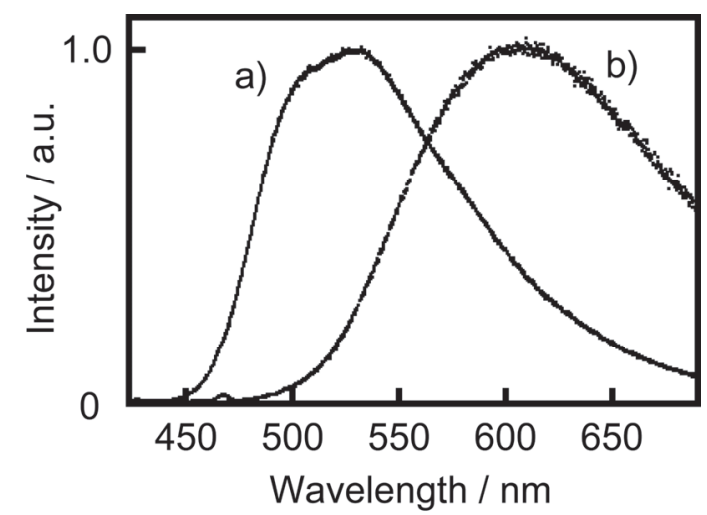

Fig. 2. Emission spectra of $\mathrm{NO}_{2}-\mathrm{F} 2 \mathrm{PA}$ in a) hexane and $\mathrm{b}$ ) toluene. $\lambda_{\mathrm{ex}}: 400 \mathrm{~nm}$.

of the molecule.

In the next stage, emission property of the amorphous film obtained by spin-coating method was investigated. Upon irradiation of the film with black light $(365 \mathrm{~nm})$, reddish yellow emission was observed at ambient atmosphere. The emission band was observed around $600 \mathrm{~nm}$ as shown in Fig. $3 \mathrm{a}$. It is noted that the emission region was somewhat similar to that in toluene solution. The fact might suggest that the electronic effect of surrounding molecules on the excited molecule was almost similar between in toluene solution and in amorphous state. Further study should be needed. When the film was exposed to hexane vapor, the emission color turned to greenish yellow and the spectrum was considerably shifted to shorter wavelength region as shown in Fig. 3b. After drying the film at ambient atmosphere, the spectrum recovered to the original. Thus, the film 
exhibited vapochromic emission. The spectrum upon exposure to hexane (Fig. 3b) was found to be similar to that in hexane solution, suggesting that the solvent molecules penetrated into the film and intermolecular interaction between $\mathrm{NO}_{2}$-F2PA and hexane caused the change in the spectrum. When the film was exposed to THF and ethanol vapors, the emission of the film was quenched. After drying the film at ambient atmosphere, the emission again appeared. It is suggested that THF and ethanol molecules also penetrate into the film resulting in intermolecular interaction to quench the emission.

Change in emission intensity of the film under the cycles of exposure to hexane vapor and drying was monitored at emission maxima of the film upon exposure to hexane vapor $(526 \mathrm{~nm})$. At ambient atmosphere, the emission intensity of the film at $526 \mathrm{~nm}$ was relatively small. When the film was exposed to hexane vapor, the emission intensity at $526 \mathrm{~nm}$ increased due to blue-shift of emission band. After drying at ambient atmosphere, the intensity again decreased. This cycle could be repeated several times although the intensity data seemed to be somewhat distributed (Fig. 4a). With regard to ethanol vapor, the emission intensity at $601 \mathrm{~nm}$ decreased upon exposure to the vapor due to quenching. When the film was dried at ambient atmosphere, the emission intensity recovered. This cycle could also be repeated several times as shown in Fig. 4b. Unfortunately, deterioration of the film quality was observed after several cycles. That might cause the data distribution.

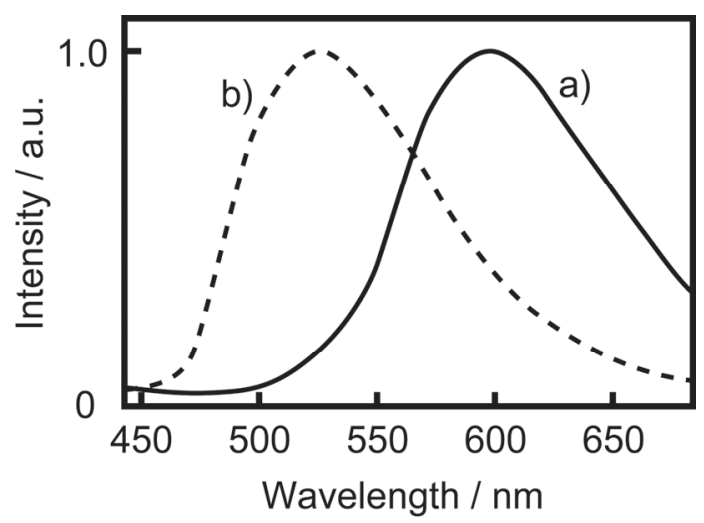

Fig. 3. Emission spectra of $\mathrm{NO}_{2}-\mathrm{F} 2 \mathrm{PA}$ film. a) At ambient atmosphere. b) Exposure to hexane vapor. $\lambda_{\text {ex }}: 365 \mathrm{~nm}$. a)

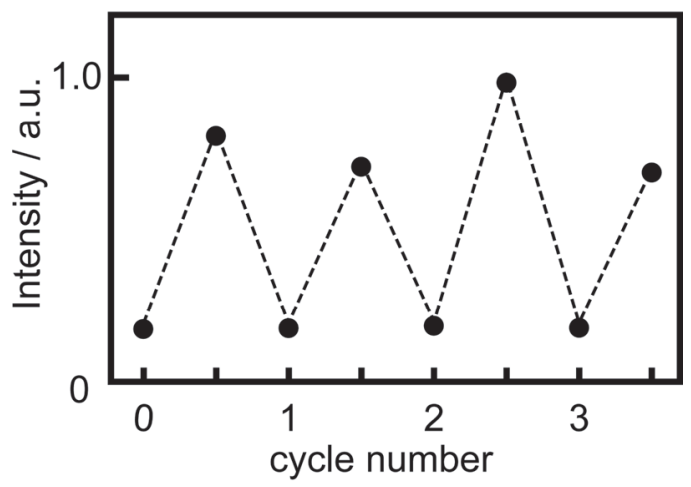

b)

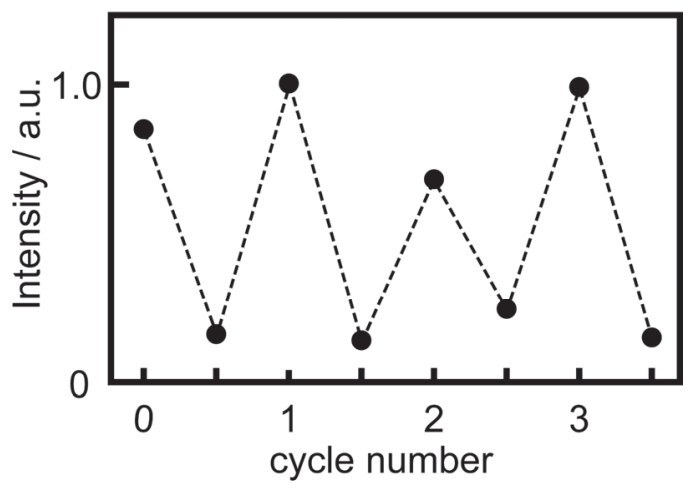

Fig. 4. Change in emission intensity of $\mathrm{NO}_{2}-\mathrm{F} 2 \mathrm{PA}$ film. $\lambda_{\mathrm{ex}}: 365 \mathrm{~nm}$. a) Exposure to hexane vapor drying cycles monitored at $526 \mathrm{~nm}$. b) Exposure to ethanol vapor - drying cycles monitored at $601 \mathrm{~nm}$.

\section{Conclusion}

An emitting amorphous molecular material, $\mathrm{NO}_{2}$-F2PA, exhibited solvatochromic emission. In addition, the amorphous film exhibited vapochromic emission. It was suggested that the solvent vapor molecules penetrated into the film and interacted with $\mathrm{NO}_{2}-\mathrm{F} 2 \mathrm{PA}$ molecule resulting in emission color change or emission quenching. Although improvement of durability seemed to be required for practical use, $\mathrm{NO}_{2}-\mathrm{F} 2 \mathrm{PA}$ and related emitting amorphous molecular materials with D-A structures are expected to be candidates of the materials for use in e.g., environmental sensors.

\section{Acknowledgements}

We would like to thank Dr. Kenji Okumoto (OKUMOTO Laboratory CO., LTD) for preparation of $\mathrm{NO}_{2}-\mathrm{F} 2 \mathrm{PA}$. This work was partly supported by JSPS KAKENHI Grant Number JP26107006 in Scientific Research on Innovative Areas "Photosynergetics". 


\section{References}

1. O. S. Wegner, Chem. Rev., 113 (2013) 3686.

2. H. Iida, S. Iwahana, T. Mizoguchi, and E. Yashima, J. Am. Chem. Soc., 134 (2012) 15103.

3. T. Hayashi, A. Kobayashi, H. Ohara, M. Yoshida, T. Matsumto, H.-C. Chang, and M. Kato, Inorg. Chem., 54 (2015) 8905.

4. R. Ishizaki and R. Katoh, Chem. Phys. Lett., 652 (2016) 36.

5. W. Ishikawa, H. Inada, H. Nakano, and Y. Shirota, Chem. Lett., 20 (1991) 1731.

6. H. Inada, K. Ohnishi, S. Nomura, A. Higuchi, H. Nakano, and Y. Shirota, J. Mater. Chem., 4 (1994) 171.

7. E. Ueta, H. Nakano, and Y. Shirota, Chem. Lett., 23 (1994) 2397.

8. H. Utsumi, D. Nagahama, H. Nakano, and Y. Shirota, J. Mater. Chem., 12 (2002) 2612.

9. T. Tanino, S. Yoshikawa, T. Ujike, D.
Nagahama, K. Moriwaki, T. Takahashi, Y. Kotani, H. Nakano, and Y. Shirota, J. Mater. Chem., 17 (2007) 4953.

10. K. Mizuguchi, H. Kageyama, and H. Nakano, Mater. Lett., 65 (2011) 2658.

11. K. Okoshi and H. Nakano, J. Photopolym. Sci. Technol., 27 (2014) 535.

12. K. Ogura and H. Nakano, Kobunshi Ronbunshu, 72 (2017) 199 (in Japanese).

13. M. Kurita, M. Momma, K. Mizuguchi, and H. Nakano, ChemPhysChem, 14 (2013) 3898.

14. K. Shishido and H. Nakano, J. Photopolym. Sci. Technol., 29 (2016) 369.

15. H. Nakano, T. Nishimura, E. Nagata, and R. Ichikawa, ChemistrySelect, 1 (2016) 1737.

16. H. Nakano, T. Takahashi, T. Tanino, and Y. Shirota, Dyes Pigm., 84 (2009) 102.

17. H. Nakano, T. Takahashi, and Y. Shirota, J. Photopolym. Sci. Technol., 22 (2009) 253. 